\title{
SUPERSTABILITY OF THE DIFFERENCE-FORM FUNCTIONAL EQUATIONS RELATED TO DISTANCE MEASURES
}

\author{
GWANG HUI KIM
}

Abstract. The present work extends the study on the stability of the functional equation $f(p r, q s)+$ $f(p s, q r)=f(p, q) f(r, s)$, which arises in the characterization of symmetrically compositive sum-form distance measures, and as a products of some multiplicative functions.

In this paper, we obtain the superstability of the functional equations

$$
\begin{aligned}
& f(p r, q s)-f(p s, q r)=f(p, q) g(r, s) \\
& f(p r, q s)-f(p s, q r)=g(p, q) f(r, s) \\
& f(p r, q s)-f(p s, q r)=g(p, q) g(r, s) \\
& f(p r, q s)-f(p s, q r)=g(p, q) h(r, s),
\end{aligned}
$$

for all $p, q, r, s \in G$, where $G$ is an Abelian group. These functional equations arise in the characterization of the nonsymmetrically compositive difference-form related to distance measures, products of some multiplicative functions. In reduction, they can be represented as exponential functional equations.

Mathematics subject classification (2010): 39B82, 39B52.

Keywords and phrases: Distance measure, superstability, multiplicative function, stability of functional equation.

\section{REFERENCES}

[1] J. K. Chung, Pl. Kannappan, C. T. Ng And P. K. Sahoo, Measures of distance between probability distributions, J. Math. Anal. Appl., 138 (1989), 280-292.

[2] PL. Kannappan And P. K. SAhoo, Sum form distance measures between probability distributions and functional equations, Int. J. of Math. \& Stat. Sci., 6 (1997), 91-105.

[3] Pl. Kannappan, P. K. Sahoo And J. K. Chung, On a functional equation associated with the symmetric divergence measures, Utilitas Math., 44 (1993), 75-83.

[4] G. H. Kim AND P. K. SAhoo, Stability of a functional equation related to distance measure - I, Appl. Math. Lett., 24 (2011), 843-849.

[5] G. H. Kim AND P. K. SAHoo, Stability of a functional equation related to distance measure - II, Ann. Funct. Anal. 1 (2010) 26-35.

[6] T. Riedel AND P. K. SAHoo, On a generalization of a functional equation associated with the distance between the probability distributions, Publ. Math. Debrecen, 46 (1995), 125-135.

[7] T. Riedel AND P. K. SAHOO, On two functional equations connected with the characterizations of the distance measures, Aequationes Math., 54 (1998), 242-263.

[8] T. RIEDEL AND P. K. SAHOO, On a generalization of a functional equation associated with the distance between the probability distributions, Publ. Math. Debrecen, 46 (1995), 125-135. 